\section{Permodelan Efisiensi Smart Home Menggunakan Mobile Programming}

EfficiencyModelling and Mobile

Programming

\author{
Suci Sri Utami Sutjipto, Septian Cahyadi, Anton Sukamto, \\ Denny Dolok \\ Program Studi Teknologi Informasi, Institut Bisnis dan Informatika Kesatuan \\ E-Mail: schayadi@ibik.ac.id
}

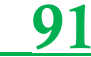

Submitted: JANUARI 2021

Accepted: JULI 2021

\title{
ABSTRACT
}

The utilization of Indonesia's electricity consumption every year continues to increase in line with national economic growth. This situation is a general description of every developing country, where the supply of electricity is not the fulfillment of the real needs of the whole but rather the ability to generate and distribute electricity to the community. Indonesia has a target to provide lighting or electricity to all citizens by 2020 or an electrification ratio of 100\%, and by 2019, the government said the realization of the electrification ratio had reached $98.89 \%$. This means that we have almost reached our target. To achieve this ambitious target, efforts have been made, including developing electricity infrastructure, such as solar power plants, to the $3 T$ (underdeveloped, frontier, and outermost) areas using the Special Allocation Fund (SAF). The existence of a smart home (smart home) allows users to remotely control parts of the house and set a schedule for activated smart home devices to help control costs and save more energy while providing added convenience and save time. So that it can save household electricity consumption and save energy. Mobile-based smart home efficiency modeling, based on temperature sensors, human movement, and light intensity sensors using a mobile-based microcontroller to help save electricity use and reduce global warming. By carrying out this research, it can facilitate community activities in controlling automation in smart homes to save electrical energy and reduce global warming. The Hardware Programming method is an approach method for designing the tools used.

Keywords: mobile programming, hardware programming, smart home.

\begin{abstract}
ABSTRAK
Pemanfaatan konsumsi listrik Indonesia setiap tahun terus meningkat sejalan dengan pertumbuhan ekonomi nasional. Keadaan ini merupakan gambaran umum dari setiap negara berkembang, dimana penyediaan tenaga listrik bukanlah pemenuhan kebutuhan riil secara keseluruhan melainkan kemampuan untuk menghasilkan dan mendistribusikan tenaga listrik kepada masyarakat. Indonesia memiliki target untuk memberikan penerangan atau listrik kepada seluruh warga pada tahun 2020 atau rasio elektrifikasi $100 \%$, dan pada tahun 2019, pemerintah menyebutkan realisasi rasio elektrifikasi telah mencapai 98,89\%. Artinya, target kita sudah hampir tercapai. Untuk mencapai target ambisius tersebut, berbagai upaya telah dilakukan, antara lain dengan membangun infrastruktur ketenagalistrikan, seperti pembangkit listrik tenaga surya, hingga ke daerah 3T (tertinggal, terdepan, dan terluar) dengan menggunakan Dana Alokasi Khusus (SAF). Keberadaan rumah pintar (smart home) memungkinkan pengguna untuk mengontrol bagian rumah dari jarak jauh dan mengatur jadwal perangkat rumah pintar yang diaktifkan untuk membantu mengendalikan biaya dan menghemat lebih banyak energi sekaligus memberikan kenyamanan tambahan dan menghemat waktu. Sehingga dapat menghemat konsumsi listrik rumah tangga dan menghemat energi. Pemodelan efisiensi rumah pintar berbasis seluler, berdasarkan sensor suhu, gerakan manusia, dan sensor intensitas cahaya menggunakan mikrokontroler berbasis seluler untuk membantu menghemat penggunaan listrik dan mengurangi pemanasan global. Dengan dilakukannya penelitian ini dapat mempermudah kegiatan
\end{abstract}

\section{JIKES}

$$
\begin{array}{r}
\text { Jurnal Informatika } \\
\text { Kesatuan } \\
\text { Vol. } 1 \text { No. 1, 2021 } \\
\text { page. } 91-96 \\
\text { IBI Kesatuan } \\
\text { ISSN xxxx - xxxx }
\end{array}
$$
DOI: $10.37641 /$ jikes.v1i1.776 
Efficiency Modeling masyarakat dalam mengendalikan otomatisasi di rumah pintar untuk menghemat energi and Mobile

Programming listrik dan mengurangi pemanasan global. Metode Hardware Programming merupakan metode pendekatan untuk merancang alat-alat yang digunakan.

Kata Kunci: pemrograman seluler, pemrograman perangkat keras, rumah pintar.

\section{PENDAHULUAN}

Seperti kita ketahui bersama bahwa peningkatan kenutuhan listruik akan sejalan dengan peningkatan pertumbuhan ekonomi secara nasional. Secara nasional, kebutuhan listrik terbesar adalah sektor industri, disusul sektor rumah tangga, usaha, dan umum. Bersumber dari website green energy efficient homes tentang electricity and global warming, untuk setiap unit energi listrik yang di produksi, tiga unit batu bara yang di bakar, terhitung tidak efisien. Dengan kondisi tingkat pendidikan yang rendah, ekonomi yang masih lemah, hingga lokasi terpencil, masih banyak penduduk yang kesulitan mendapatkan akses energi listrik. Upaya untuk mengatasi persoalan tersebut sebenarnya sudah dilakukan oleh pemerintah.

Perkembangan yang pesat dibidang teknologi, elektronik, telekomunikasi maupun mekanik telah menghasilkan berbagai aplikasi canggih dan cerdas yang merubah kehidupan manusia pada saat ini dan mendatang. Pada kenyataannya sebagian besar rumah hanya dijadikan tempat peristirahatan, sedangkan untuk mengontrol ataupun memonitor dilakukan dengan cara manual, dengan kata lain dikerjakan sendiri oleh pemilik rumah. Terkadang muncul pemikiran untuk memiliki rumah yang benar-benar bisa mengerti keinginan pemiliknya, membayangkan rumah pintar (smart home) untuk bisa mengurangi beban kerja di rumah. Dengan adanya rumah pintar yang memungkinkan pemiliknya untuk kontrol jarak jauh bagian rumah dan mengatur jadwal waktu untuk perangkat rumah pintar yang diaktifkan untuk membantu biaya kontrol dan lebih hemat energi sambil memberikan kenyamanan ditambahkan dan menghemat waktu. Sehingga dapat menghemat konsumsi listrik rumah tangga dan hemat energi. Untuk mewujudkan hal tersebut, maka pada sistem pengendali otomatis yang dapat mengendalikan aktif atau tidak aktifnya lampu dengan menggunakan sensor yang terintegrasi dengan mikrokontroler berdasarkan pembacaan terhadap intensitas cahaya di sekitar.

Ruang lingkup pada sistem ini dibatasi dengan pembuatan nodel, dibuat menggunakan Mikrokontroler ATMega 328. Pemanasan suhu menggunakan media lampu pijar yang diatur oleh arduino menggunakan rangkaian dimmer lampu tersebut dapat diatur dengan menurunkan dan menaikan itensitas cahaya. Untuk pemrograman dalam mikrokontroler Atmega328 hanya sebatas pemrograman untuk pengaturan suhu dan pergerakan manusia pada alat ini.

Metode Hardware Programming merupakan sebuah metode pendekatan untuk merancang alat yang digunakan. Dengan tujuan membuat suatu model rumah pintar efesien berbasis mobile, berdasarkan sensor suhu, pergerakan manusia dan sensor intensitas cahaya dengan menggunakan mikrokontroler berbasis mobile dalam upaya untuk membantu penghematan penggunaan energi listrik dan mengurangi pemanasan global dan dapat mempermudah kegiatan manusia dalam pengendalian otomatisasi pada rumah pintar dalam upaya penghematan energi listrik.

\section{METODE PENELITIAN}

Metode penelitian yang digunakan dalam pembutan model ini adalah Metode Hardware Programming. Metode Hardware Programming Model Rumah Pintar Efisien Berbasis Mobile melalui beberapa tahap pembuatan. Tahapan tersebut dapat dilihat pada gambar 1 dengan uraian setiap tahapan sebagai berikut :

1. Perencanaan Proyek Penelitian (Project Planning). Pada tahapan ini, terdapat beberapa hal yang perlu adanya penentuan dan pertimbangan seperti : 
a. penentuan topik/judul penelitian,

b. estimasi kebutuhan alat dan bahan,

Efficiency Modeling

c. estimasi anggaran, dan

d. kemungkinan penerapan dari aplikasi yang dirancang.

2. Penelitian (Research), di tahap ini bisa dilakukan apabila tahap perencanaan telah benar-benar matang. Tahap awal penelitian dilakukan dengan proses pengetasan komponen yang dibutuhkan dan kemungkinan rancangan awal dan akhir dari kebutuhan sistem

3. Past Testing (Pengetesan Komponen), Di tahap ini dilakukan pengetesan komponen-komponen yang akan digunakan berfungsi atau tidak menggunakan multimeter.

4. Mechanical Design (Desain Sistem Mekanik), yaitu tahap perancangan perangkat keras, di sini desain mekanik merupakan hal yang penting yang harus dipertimbangkan.

5. Electrical Design (Desain Sistem Listrik), Di tahap ini harus memperhatikan beberapa tahap, yaitu :

- sumber catu daya,

- kontroler yang digunkan,

- desain driver dan

- sistem kontrol yang akan diterapkan.

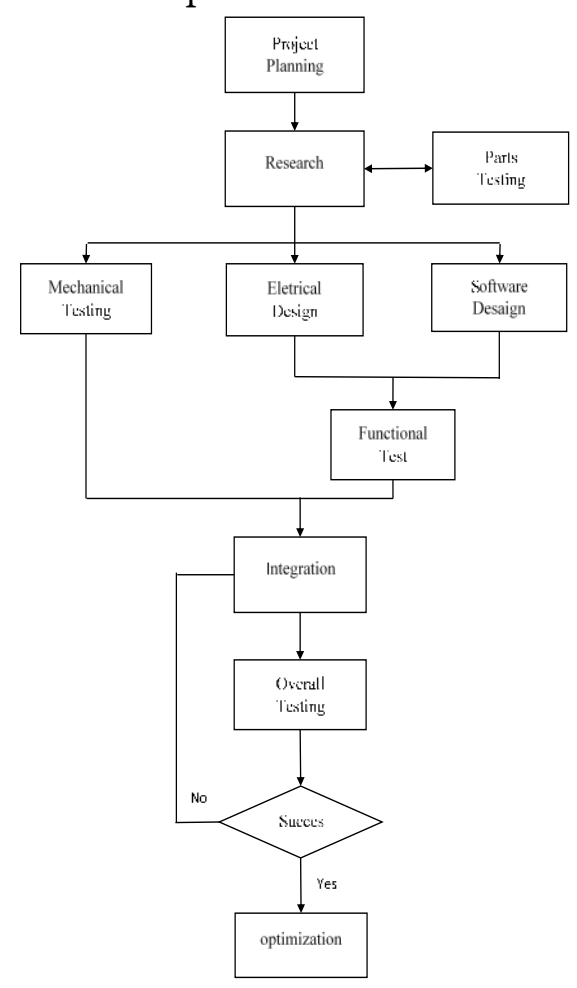

Gambar 1 Tahapan Programming

6. Software Design (Desain Perangkat Lunak), Software Design yang digunakan dalam penelitian ini adalah perangkat lunak Arduino IDE 1.6.8 guna memasukkan program pada board arduino.

7. Functional Test (Tes Fungsional), Functional Test ini dilakukan untuk meningkatkan kinerja dari perangkat lunak untuk pengontrolan desain listrik dan mengeliminasi error (bug) dari software tesebut.

8. Integration (Integrasi atau Perakitan), Modul listrik yang diintegrasi dengan software di dalam kontrolernya, diintegrasikan dalam struktur mekanik yang telah dirancang. Dan dilakukan tes fungsional keseluruhan sistem. 
Efficiency Modeling and Mobile

Programming
9. Overall Testing (Tes Fungsional Keseluruhan Sistem), Di tahap ini dilakukan pengetesan fungsi dari keseluruhan sistem.

10. Optimization (Optimasi Sistem), Dilakukannya optimasi sistem guna meningkatkan kinerja dari aplikasi yang telah dirancang. Optimasi ditekankan pada sistem mekanik agar outputnya sesuai dengan yang diharapkan.

Alat dan Bahan penelitian yang digunakan berdasarkan

a. Teknologi yang digunakan seperti : Arduiono 1.6.7, Laptop Lenovo, AMD E1, RAM $4 \mathrm{~Gb}$ dan operating system windows 10

b. Mekanik yang digunakan seperti : Multimeter, Akrilik, Jumper, Obeng dan tang, Solder dan penyedotnya

c. Bahan penelitian yang digunakan : Motor Driver, Arduiono Uno, Blower, Modul Bluetooth, Lampu pijar, Sensor LDR, Sensor DHT11, sensor PIR, Motor servo

\section{HASIL DAN PEMBAHASAN}

Di awal telah dijelaskan proses perancangan hingga implementasi Rancang Bangun permodelan efisiensi smart home menggunakan mobile programming dengan rancangan suatu sistem otomatisasi menggunakan mikrokontroler. Rancangan model otomatisasi ini diimplementasikan dengan menggunakan modul-modul elektronik yang dibutuhkan tetapi dalam penempatan komponen elektronik disesuaikan dan diusahakan tidak banyak memakan tempat menggunakan komponen berbahan akrilik.

Tampilan Keseluruhan

Pada tampilan ini dibuatlah simulasi dari bentuk persegi panjang bertujuan supaya rangkaian mempermudah dalam penempatan alat serta komponen- komponen pendukung sistem rangkaian.

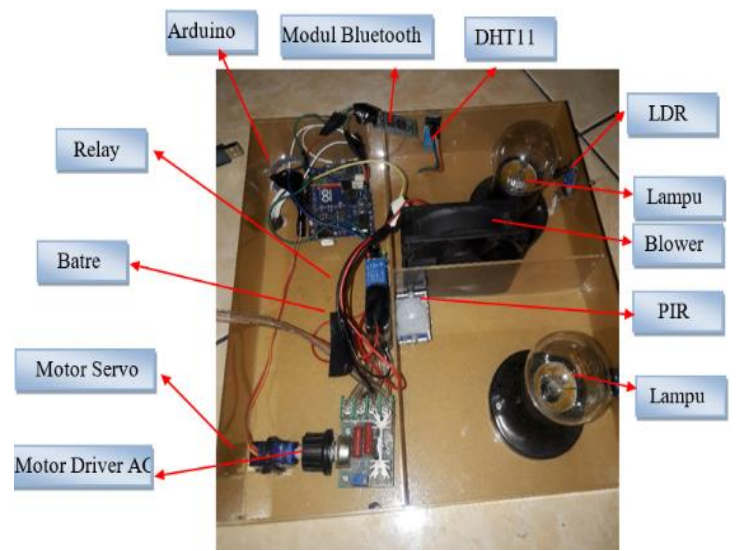

\section{Pembahasan Sistem}

Gambar 2. Rangkaian simulasi model

Pada tahapan ini akan dibahas mengenai cara kerja dari inputan yang telah dirancang. Dimulai dengan pemberian catu daya sampai dengan sensor PIR, DHT11, LDR dapat bekerja dengan baik. Setelah rangkaian dalam keadaan siap maka sensor PIR, DHT11, LDR akan membaca keadaan suhu ruangan, keberadaan gerak dalam ruangan dan pendeteksian cahaya maupun suara. Setelah itu data yang telah berhasil dibaca oleh sensor akan di kirimkan ke arduino.

\section{Overall Testing (Pengujian Fungsional Keseluruhan Sistem)}

Setelah rangkaian dalam keadaan siap maka sensor PIR, DHT11, LDR akan membaca keadaan suhu ruangan, posisi gerak dalam ruangan dan pendeteksian cahaya maupun suara. Setelah itu data yang telah berhasil dibaca oleh sensor akan di kirimkan ke arduino.

Proses yang dilakukan oleh arduino adalah mengambil setiap data dengan jeda 1 detik yang kemudian memperosesnya dan memproses untuk pembacaan data dari setiap nilai sensor. 
Tahapan ini dilakukan dengan tujuan untuk mengetahui apakah system yang sudah dibuat sesuai dengan rancangan yang sudah ada. Uji coba ini dilakukan dengan menguji pin analog 0 hingga pin 10 untuk input dan output.

\section{Pengujian Fungsional}

Di tahapan ini akan diuji apakah semua komponen dapat berfungsi dengan baik. Untuk pengujian perangkat keras yang digunakan adalah multimeter dengan pada satuan daya DC volt, dimana pena positif pada multimeter dihubungkan ke vcc dan pena negative pada multimeter dihubungkan ke Ground.

\section{Pengujian Catu Daya Modul Arduino}

Pengujian blok catu daya modul arduino dilakukan dengan cara melakukan pengukuran tegangan yang dihasilkan oleh adaptor. Cara pengukuran dilakukan oleh

- multimeter,

- $\quad$ pena positif dihubungkan pada tegangan 5 volt dan

- $\quad$ pena negative dihubungkan dengan ground pada mikrokontroler.

\section{Pengujian Catu Daya Lampu}

Pengujian blok catu daya lampu dilakukan dengan cara melakukan pengukuran tegangan yang dihasilkan oleh terminal listrik.

\section{Pengujian Validasi}

Tahap ini dilakukan dengan tujuan untuk mengetahui sistem yang dibuat sudah bekerja dengan benar atau tidak. Pengujian dilakukan dengan cara mengaktifkan rangkaian dan melakukan pengetasan di permukaan yang bebas hambatan kemudian memberikan hambatan pada sensor satu dan dua agar dapat berfungsi sebagaimanamestinya.

Tabel 1 Hasil Validasi Komponen

\begin{tabular}{|c|l|l|l|}
\hline No & \multicolumn{1}{|c|}{ Uji Sensor } & \multicolumn{1}{|c|}{ Kondisi } & \multicolumn{1}{c|}{ Keterangan } \\
\hline 1 & LDR & Ada Cahaya & Mengirimkan Nilai pulsa ke android \\
\hline 2 & DHT11 & Suhu & $\begin{array}{l}\text { Mengirimkan nilai suhu kedalam } \\
\text { android }\end{array}$ \\
\hline 3 & PIR & Gerakkan & Mengirim nilai gerak android \\
\hline
\end{tabular}

\section{Sumber: Data Primer}

\section{Kerja Sistem}

Tahapan awal adalah sistem yang akan digunakan sudah siap. Pada tahap ini adalah tahap keseluruhan dimana sistem sudah dapat bekerja sesuai dengan rencana, sensor suhu,gerak dan ldr mampu memberikan respon terhadap model dan mengirimkan data pada android.

\section{Aplikasi}

Sistem yang telah dibuat sudah bekerja dengan baik, namun masih dapat dioptimalkan untuk memaksimalkan performa dari alat yang dibangun. Optimalisasi dapat dilakukan dengan meletakkan komponen pada tempat yang tahan air. Model alat hendaknya diletakan pada posisi dimana alat dapat bekerja secara maksimal.

\section{Cara Perhitungan Alat Secara Manual}

Pada tahapan ini adalah cara menghitung cara kerja atau hasil alat yang dibuat, sebelumnya kita harus tahu terlebih dahulu tarif dasar listrik rumah tangga R1. Dan beberapa golongan tarif/daya rumah tangga :

1. R-1 Rumah tangga kecil ditegangan rendah, daya 1.300 VA - 2200 VA

2. R-2 Rumah tangga Menengah ditegangan rendah, daya 3.500 VA - 5.500 VA

3. R-3 Rumah tangga besar ditegangan rendah, daya 6.500 VA keatas

(https://id.wikipedia.org/wiki/Tarif_dasar_listrik)

Di alat ini, digunakan satu buah lampu bohlam yang dimana tegangannya 15 watt. Golongan tarif listrik yang saya gunakan dialat ini yaitu golongan R-1, yang dimana dayanya antara 900 VA - 2200 VA. Dialat ini saya menggunakan tegangan 900 VA 
Efficiency Modeling and Mobile Programming dengan tarif satu kilo watt perjam 320 rupiah $(1 \mathrm{Kw} / \mathrm{h}=\mathrm{Rp} .320)$. Rumus dan cara perhitungan alatnya sebagai berikut :

a. Terlebih dahulu diubah $1 \mathrm{Kw} / \mathrm{h}$ ke dalam 1 watt berapa rupiah, karena dialat ini saya menggunakan satuannya dalam watt

$1 K w / h=R p .320: 1000 w / s=R p .0,32 w / s \ldots$. (i)

b. Saya masukan hasil perhitungan pertama kedalam satuan rupiah/jam

\begin{tabular}{|l|l|l|}
\hline Tegangan Input (volt) & Tegangan Input VSS & Tegangan Output \\
\hline 220 Volt & 220 Volt & 220 Volt \\
\hline
\end{tabular}

\section{Rumus :}

$R p=$ Watt....(i) $x$ Watt bohlam $=R p . .$. .

0,32 watt $x 15$ watt $=R p \cdot 6,4$ (dalam satuan perjam)

$1 \mathrm{jam}=3600$ detik

Rp. 6,4 jam : 3600 detik $=$ Rp. 0,0017777

dan dibulatkan menggunkan sensor dialat tersebut biaya tarifnya menjadi Rp. 0.001 . Jadi, satu buah lampu bohlam dengan tegangannya 20 watt bisa menghasilkan tarif biaya Rp. 0,001/detik. Kalau saya memakai lampu bohlam selama 10 jam (10 jam x 3600 detik $=36000$ detik) maka biaya yang dikeluarkan sebesar 36000 detik x 0,00177 detik $=R p$. 63.720. Sedangkan jika lampu bohlam dihitung dengan sensor maka 36000 detik x 0,001 detik $=$ Rp. 36.0. Terlihat perbedaannya dari alat tersebut dari yang tidak menggunakan sensor dengan yang mengunakan sensor selisih nya cukup lumayan yaitu Rp. 7.200.

\section{PENUTUP}

Dari hasil pengujian didapatkan hasil yang cukup memuaskan dikarenakan hasilnya sama dengan yang diharapkan. Saat pengujian respon dengan adanya aktivitas dan tidak adanya aktivitas pengiriman data pulsa terhadap android. Pada pengujian Sensor DHT11 ketika tidak ada aktivitas blower tidak berfungsi dan ketika ada aktivitas blower tersebut berfungsi, selanjutnya sensor PIR ketika tidak ada aktivitas lampu akan meredup dan ketika ada aktivitas lampu tersebut terang, dan pada Mobile/android ketika tidak ada aktivitas suhu suatu ruangan masih diangka 25 derajat celcius dan ketika ruangan tersebut ada aktivitas suhu menjadi 28 derajat celcius. Pada hasil akhir didapat nilai perhitungan sebesar Rp. 7,200 (rupiah).

Pada saat penggunaan sensor yang tepat, gunakan sensor yang hanya dapat mengenali atau yang memang ditargetkan, seperti melalui voice recognition. Ruang lingkupnya pun diperluas agar penempatan sensor satu dan lainnya agar dapat bekerja maksimal. Ganti modul bluetooth dengan alat Ethernet Shield untuk hasil yang maksimal agar bisa menampilkan output dari alat tersebut dari jarak yang lebih jauh dari modul bluetooth.

\section{DAFTAR PUSTAKA}

[1] Indah, Ary, I, 2014. Sistem Otomatisasi Pengendali Lampu Berbasis Mikrokontroler. STMIK PalCOmTech, Palembang.

[2] Laumal, Folkes, 2017. Implementasi Mikrokontroler Atmega328 Di Bidang Pertanian Dan Industri, Samudra Biru, Jogjakarta

[3] Marta, Yuwono, D. 2016. Arduino Itu Pintar. PT. Elex Media Komputindo, Jakarta.

[4] Ma'mun. Syukron. 2010. Rancang Bangun Sistem Otomasi Lampu Dan Pendingin Ruangan. Skripsi. Universitas Indonesia, Jakarta.

[5] Mulyana, M., 2012. Consumer Behaviour: Sukses Dengan Memahami Konsumen.

[6] Otomo, Galoeh. \& Wildian. 2013. Sistem Kontrol Pelayanan Lampu ruangan Berdasarkan Pendekteksian Ada Tidaknya Orang Di Dalam Ruangan. Padang. Jurnal Fisika UNAND. Vol.2, No.4

[7] Setiaji, Donny. 2014. Smart Home. www.donnysetiaji.blogspot.co.id. 12 Agustus 2014.

[8] Wardoyo, Siswo, \& Suryo, Anggoro. 2015. Pengantar Mikrokontroler dan Aplikasi pada Arduino. Teknosain, Yogyakarta. 